\title{
Characteristics of married adolescent girls in Egypt [Arabic]
}

\author{
Nahla G. Abdel-Tawab \\ Population Council \\ May Gadallah \\ Doaa Oraby \\ Population Council
}

Follow this and additional works at: https://knowledgecommons.popcouncil.org/departments_sbsr-pgy

Part of the Demography, Population, and Ecology Commons, Domestic and Intimate Partner Violence Commons, Family, Life Course, and Society Commons, International Public Health Commons, and the Maternal and Child Health Commons

How does access to this work benefit you? Let us know!

\section{Recommended Citation}

Abdel-Tawab, Nahla G., May Gadallah, and Doaa Oraby. 2017. "Characteristics of married adolescent girls in Egypt," Policy brief. Cairo: Population Council. [in Arabic] 


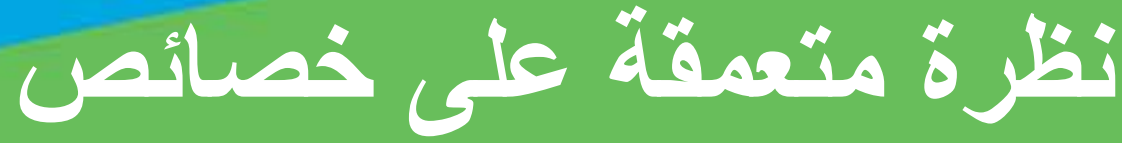 الزوجات الصغيرات في مصر غلئر}

دـ نهلة عبد التواب' دـ مي جاد اللهُ د. دعاء عرابيץ

(مجلس السكان الدولي وقسم الصحة العامة بجامعة

ومن الناحية الاجتماعية فإن الزواج المبكر يحرم الفتاة

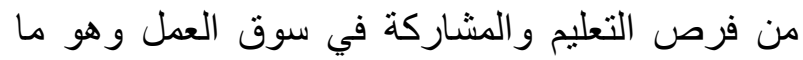
يكرس من ظاهرة القر لدى تلك الأسر أما بالنسبة للأبناء

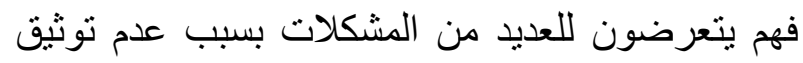

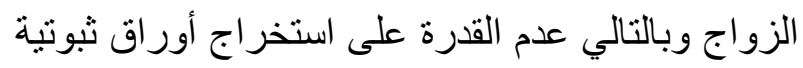

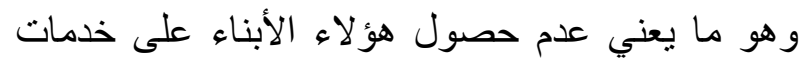
صحية أو تعليمية.

\section{حوالى ، . 7 ألف سيدة على مستوى الجمهمرية ثزوجن قيل بلوغ سن م ا سنة.}

وبالر غم من انتشار الزواج المبكر وخاصة في المناطق الريفية إلا أن معظم البحوث ركزت التمار الزواج على محاولة فهم أسباب الزو اج المبكر أو التعرف على التح العو اقب الاجتماعية

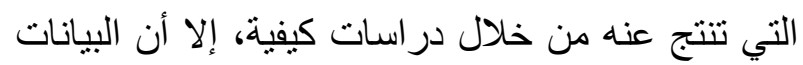
الكمية التي تتعلق بالزوجات الصغير ات (تحت مل م سنة)

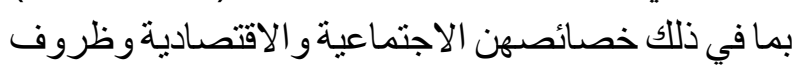

بالر غم من ارتفاع متوسط سن الزواج في مصر (· ب عاماً

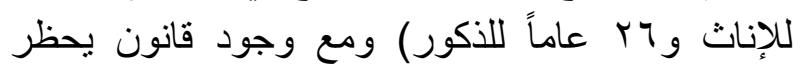

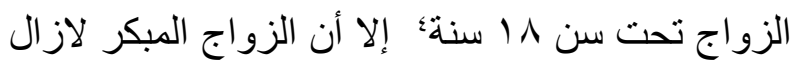

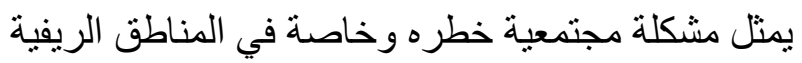

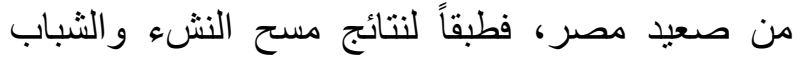

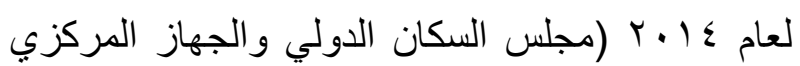

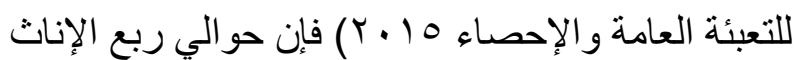

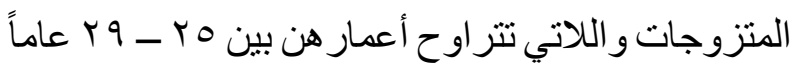

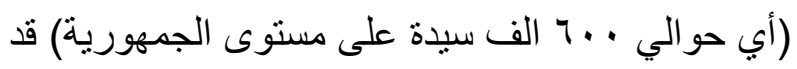

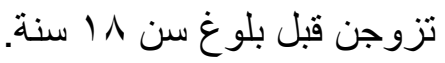

وترتفع هذه النسبة لتصل إلى ب,rr\% بين الإناث

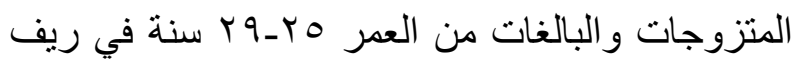

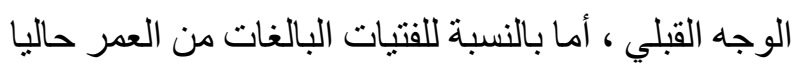

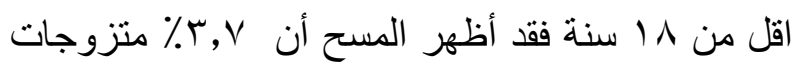
بالفعل بالإضافة إلى ب, \% \% مخطوبات. و وتمثل هاتين

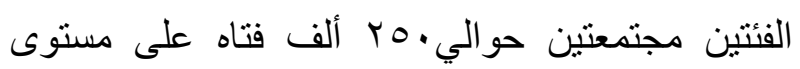

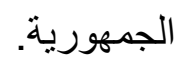

ويمثل الزواج المبكر مخاطر صحية عديدة على الفتاة

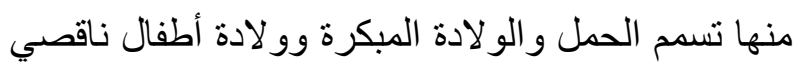

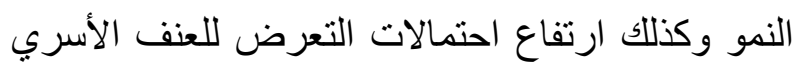

ا ممثل مجلس السكان الدولي - القاهرة

r r مدرس الإحصاء بكلية الاقتصاد و العلوم السياسية - جامعة القاهرة ب باحث أول في دراسات الصحة الإنجابية ـ مجلس السكان الدولي ـ القاهرة 


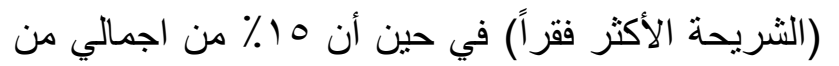

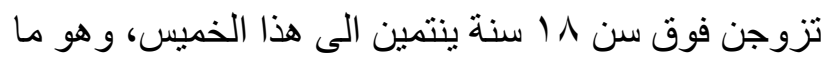
يشير الى علاقة الفقر بالزواج المبكر حيث أن الأكثر فقراً

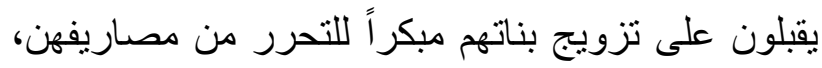

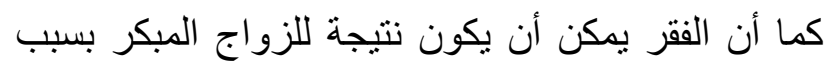

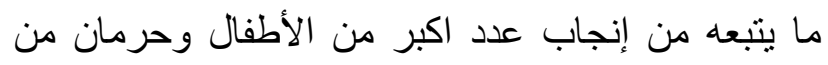

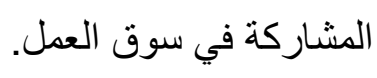

\section{السيدات اللاتى ثزوجن ثيت سن 1 انة أكثر عرضة لزواج الأثقارب وكذالك للزواج من رجال يكبروهن بعد أكبر من السنوات.}

يشير التحليل الثانوي لنتائج مسح النشء و الثباب لعام

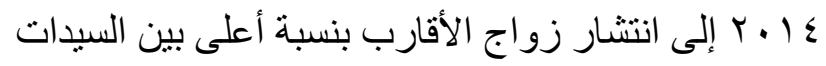

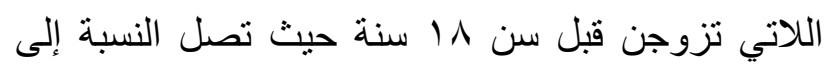

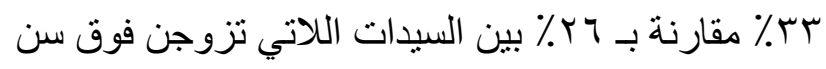

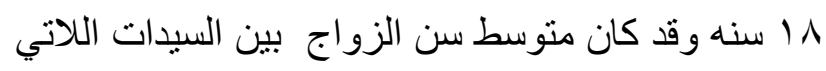

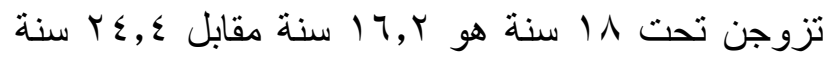

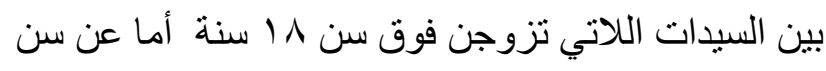
الزواج والفارق العدري بين الزوجين فتشير النتائج إلى

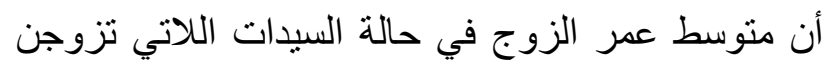

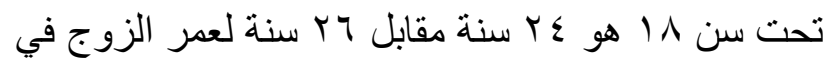

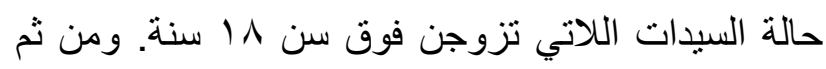

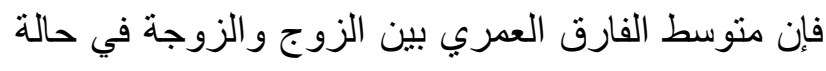

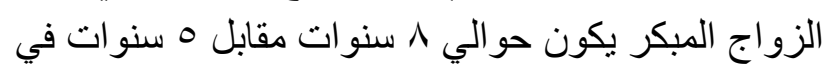

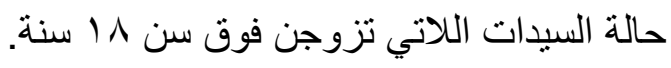

\section{تخذفض معدلات المشاركة في سوق}

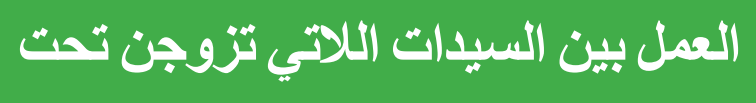

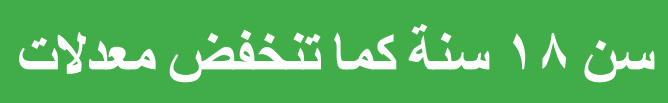
مشاركتهن في العياة السياسية.
معيشتهن و اتجاهات الر أي لديهن تكاد تكون منعدمة وذللك

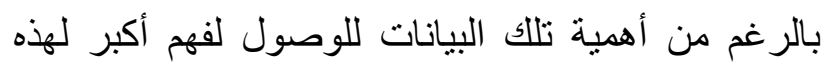

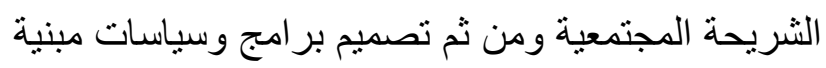

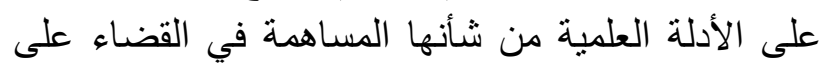

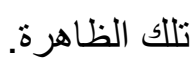

ويعرض هذا الملخص أهم النتائج لتحليل جزء من بيانات

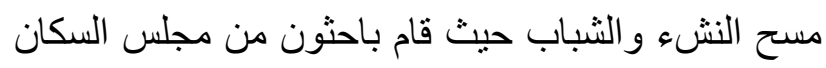

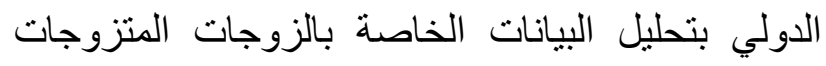

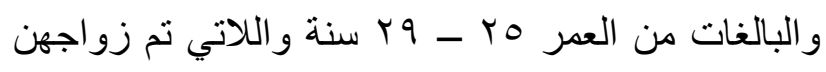

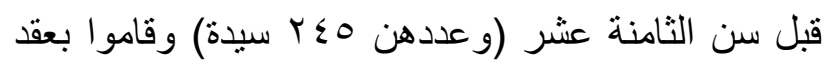
مقارنات بخصوص مجموعة من الخصائص الاجتماعية

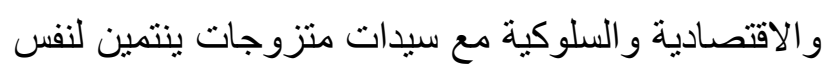
الفئة العمرية ولكن تزوجن بعد سن الثامنة عثر (و عددهن

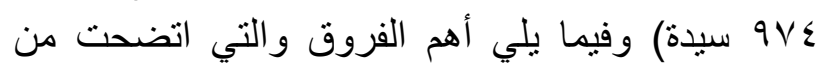
المقارنة بين المجموعتين.

\section{أهم التنائج}

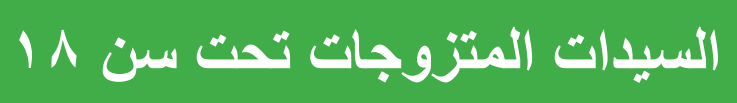

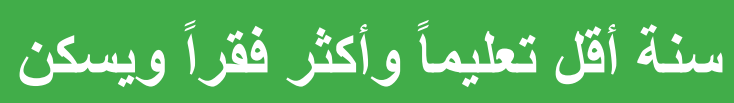

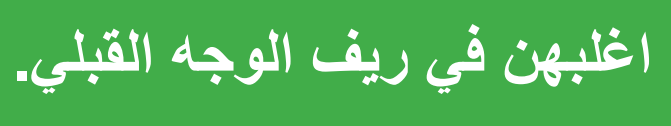

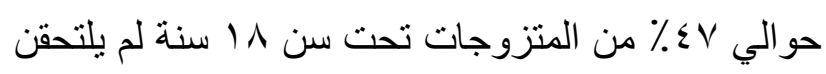

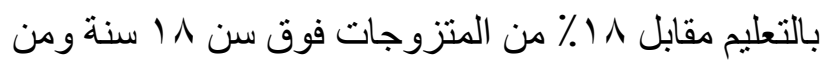

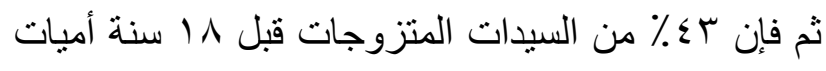

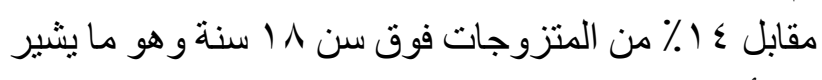

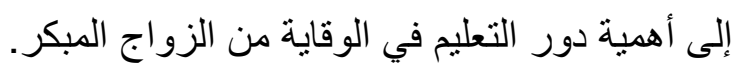
ومن ناحية التوزيع الجغر افي نتير البيانات إلى أن الزواج

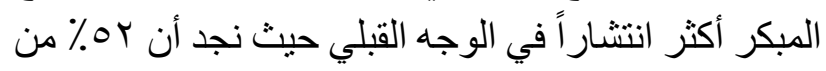

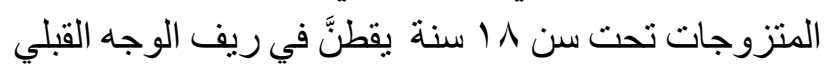

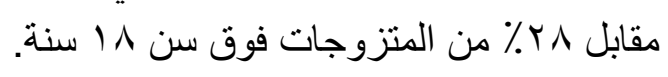
كما تشير البيانات الى أن ثلث السيدات اللاتي نزوجن تحت

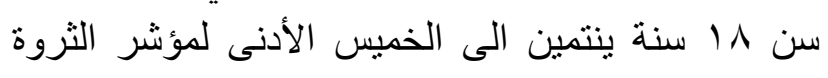




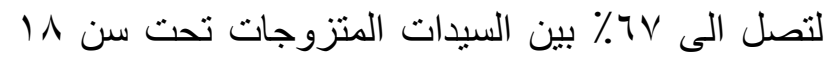

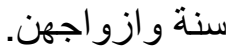

ولقياس مدى السعادة الزوجية بين هذه الاسر سئلت السيدات

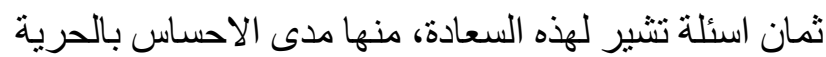

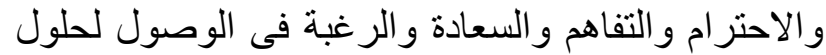
مشتركة و غياب الخلافات و الخشونة فى التعامل.

وبمقارنة مجموعتي السيدات، اشارت السيدات اللاتي

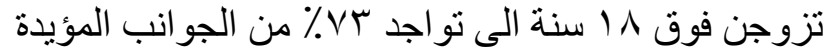

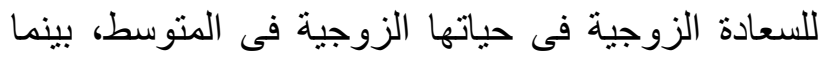

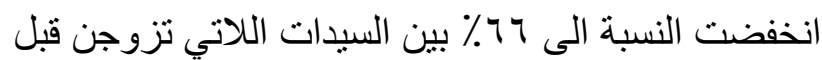

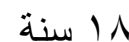

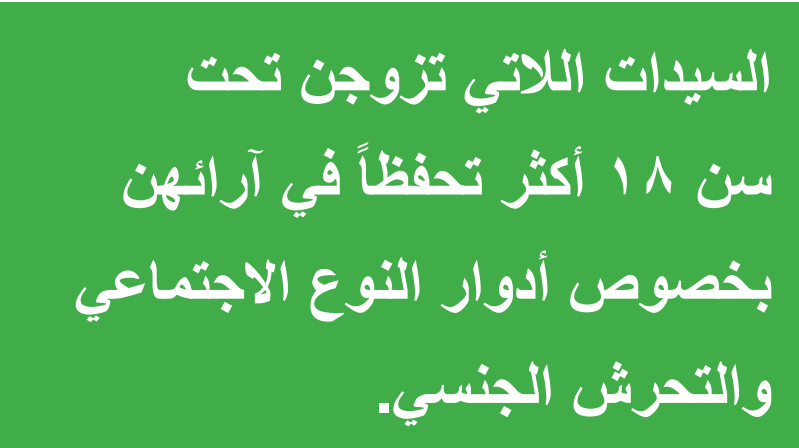

بسؤال السيدات المتزوجات و البالغات من العمر هب ـ ب ب

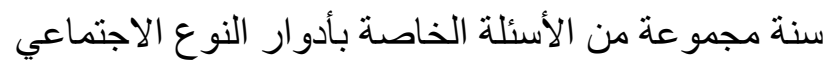
(على سبيل المثال أحقية الولد في التعليم عن البنت و إعطاء الأولوية في التوظيف للذكور، ودرجة تقبلهن لمشاركة التهن

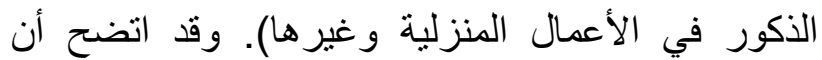

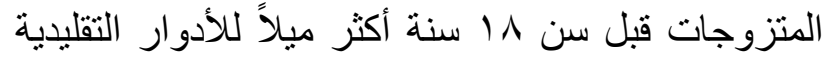

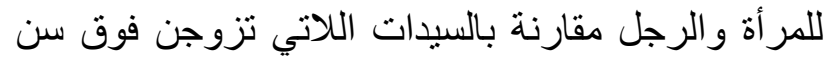

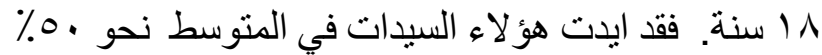

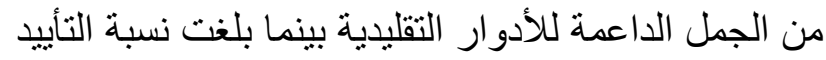

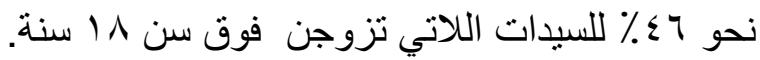

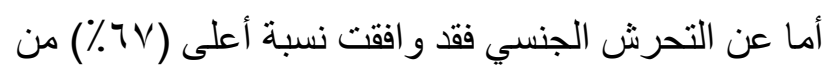

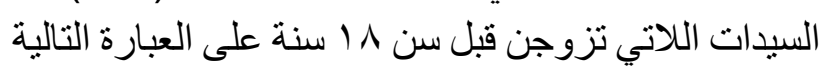
》السيدة التي ترتدي ملابس مستفزة تستحق أن يتحرش

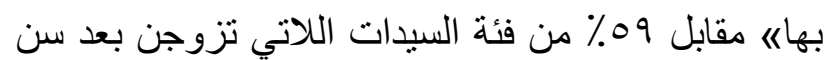

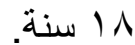

افادت حوالي با ٪ من السيدات اللاتي تزوجن تحت

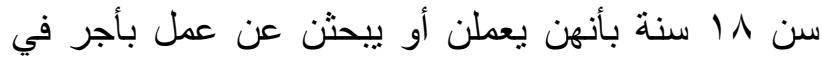

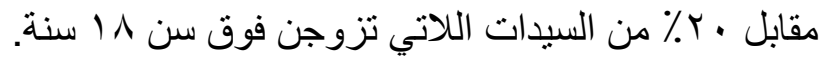

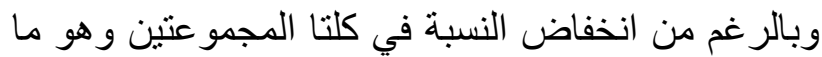
يرجع إلى العديد من الأسباب الاجتماعية و الاقتصادية،

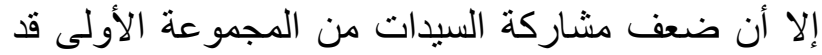

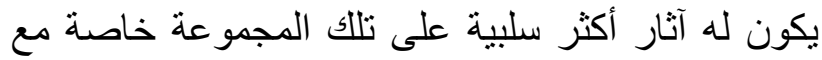
الأخذ في الاعتبار ارتفاع نسبة الفقر وزيادة عدد الأطفال

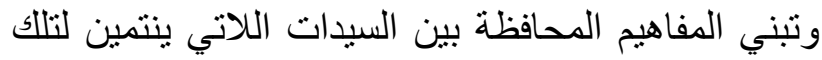

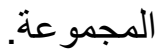

و على صعيد المشاركة السياسية أفادت . 7٪ من السيدات

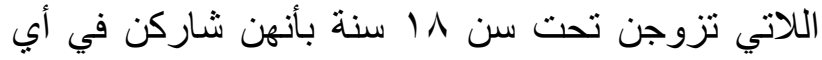

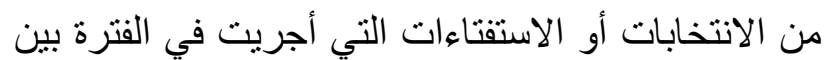

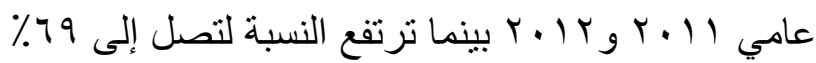
بين فئة السيدات اللاتي تزوجن فوق سن ^/ ل سنة.

وقد يرجع ضعف المشاركة السياسية بين فئة السيدات

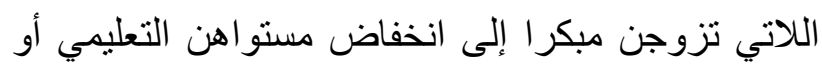

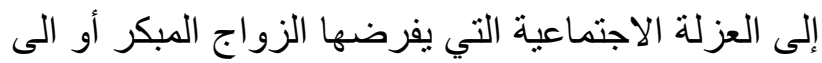
غياب الأوراق الثبوتية كما هو الحال لادى بعض السيدات في ريف الوجه القبلي.

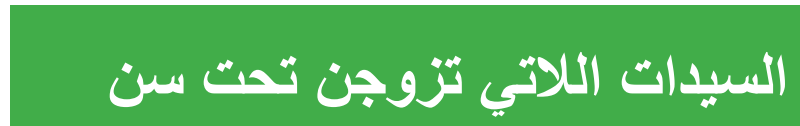 1 انهة أفقل ثواصلاً مع أزواجهن وأثل سعادة في حياتِهن الزوينة.}

سئلت السيدات المتزوجات في الفئة العمرية ه ب ـ و سنة عن تواصلهن مع أزو اجهن ومدى مداومتهن على مناقتشة

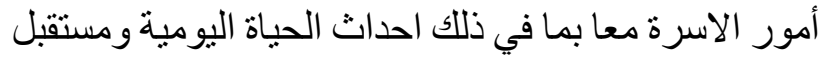

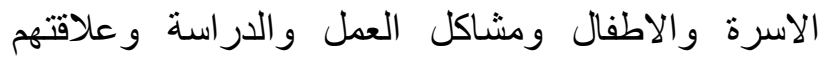

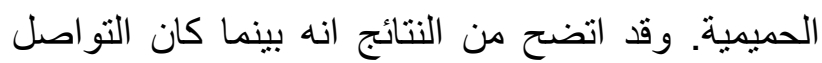

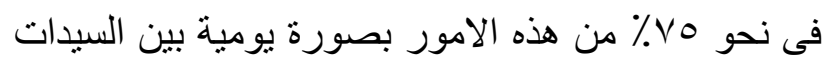

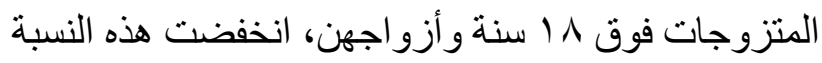


ومما سبق بمكن أن نستخلص أن هؤلاء السيدات اللاتي

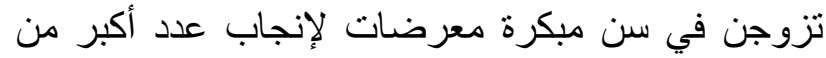

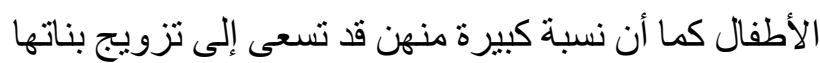

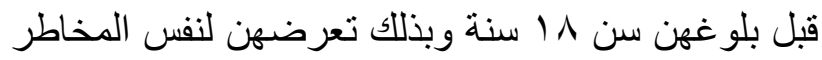
و المشكلات اللاتي تعرضن لهن لها.

\section{السيدات اللاتي تزوجن تحت سن} 1 1 سنة أكثر معرفة بوسائل تنظيم الأسرة ولكثهم أقل استخداماً لتشأك

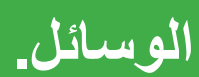

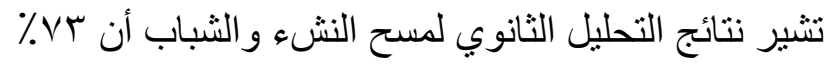

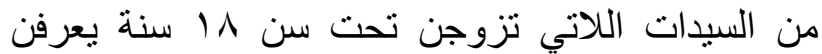

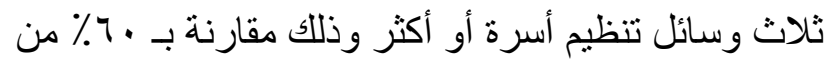

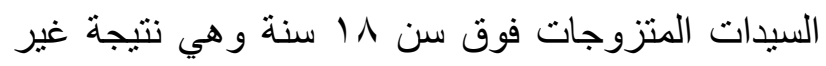

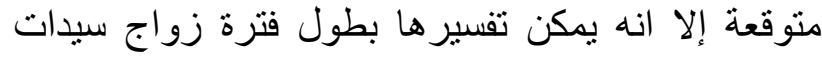

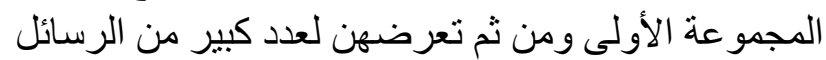

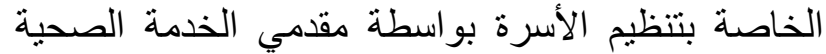

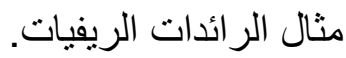

أما عن معدلات استخدام وسائل تنظيم الأسرة (السابق أو

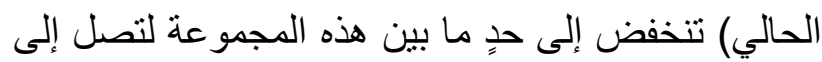

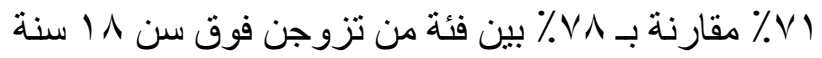

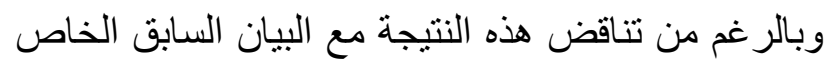

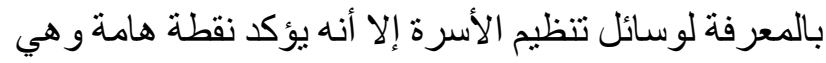

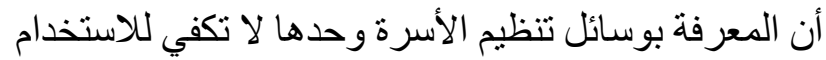

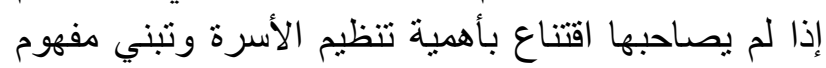

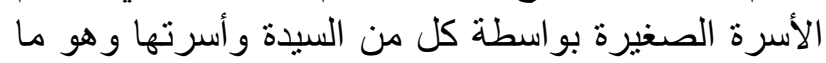

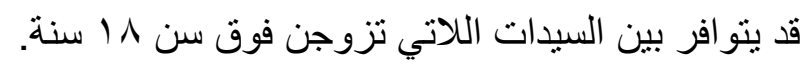

السيدات الملاتي ثزوجن تحث سن 1 1 سنة ينيبن عدد أكبر من الأطفال ويثمرضن بنسبة أعلى للإجهاض وولادة طلم ميت.

\section{السيدات النلاتي تزوجن تحت سن}

\section{1 سنة أكثر تأيبداً للعنف الأسري ولاستمرار عادة ختان الإناث.}

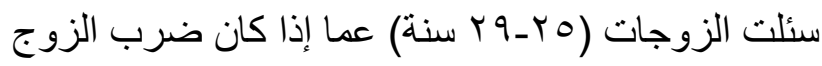

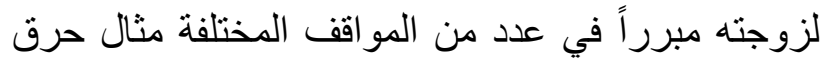

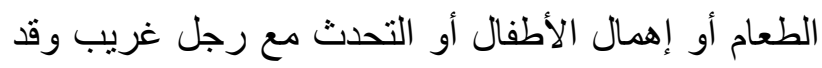

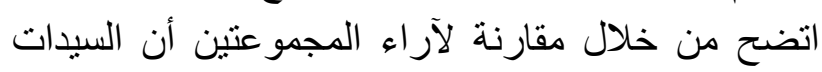

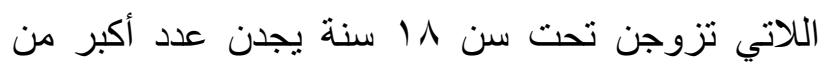

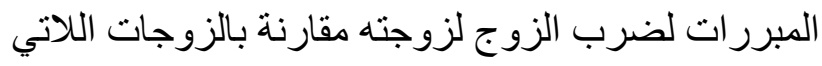

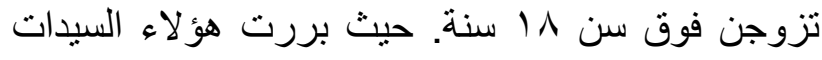

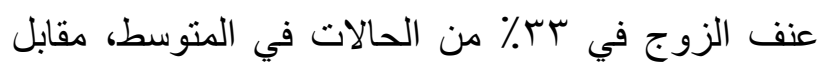

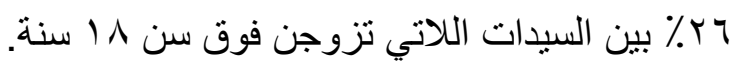

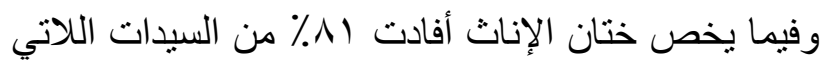

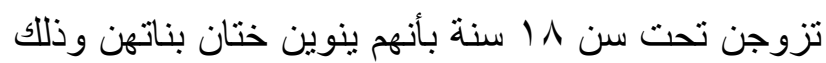

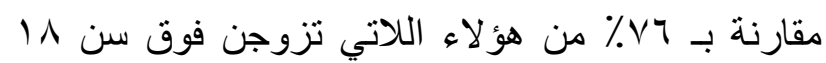
سنة. - مقارنة

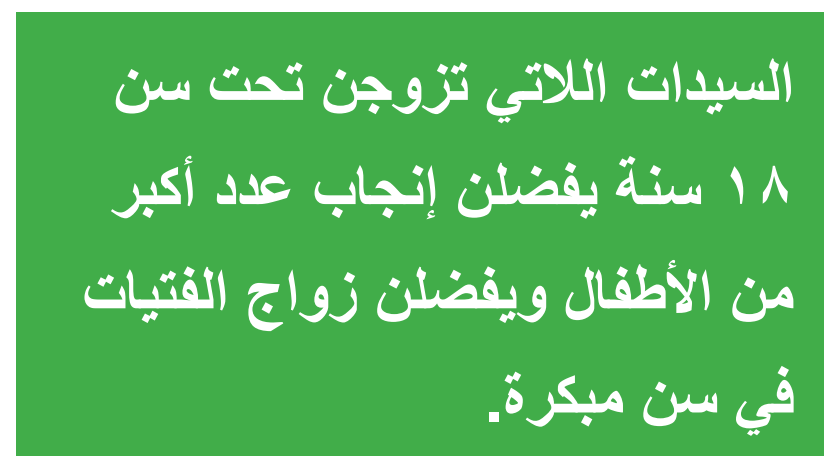

سئلت السيدات المتزوجات ه ب ـ ب سنة عن العدد الأمثل للأطفال في الأسرة وكان منوسط العدات العزد الأمثل بالنسبة لمن العن

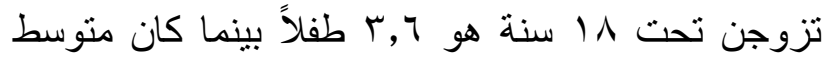

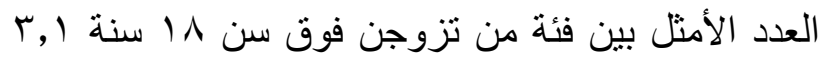

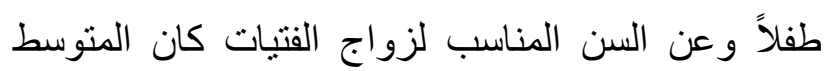

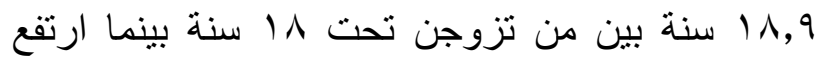

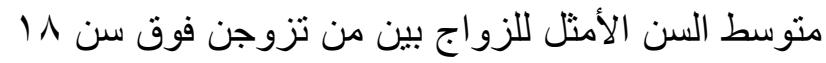
سنة ليصل إلى r, • r سنة. 
الأكثر عرضة للزواج المبكر كما أنها تساعدنا في تحديد

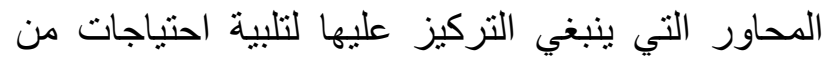
تزوجن بالفعل.

إن القضاء على مشكلة الزو اج المبكر لن يسهم فقط في حماية

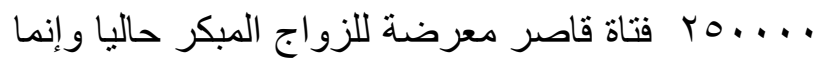
سوف يسهم في حماية حوالي مليون طفل سوف تتجبهن

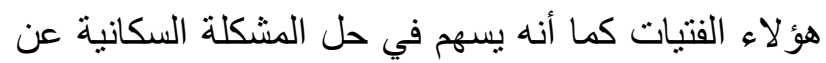
طريق خفض معدلات الإنجاب وتحسين خصائص السكان

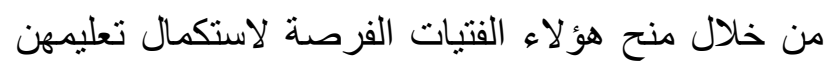

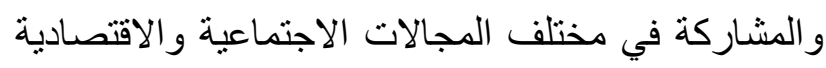

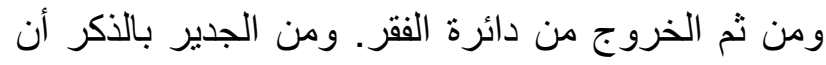

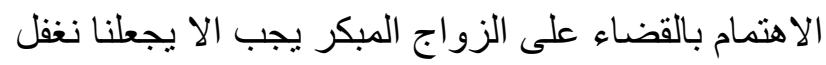

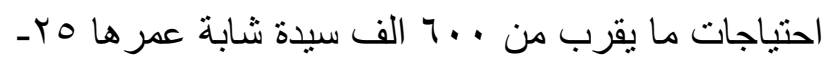

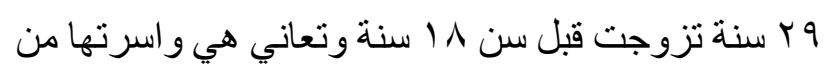
مشكلات صحية واجتماعية و اقتصادية.

\section{التوصيات}

وفيما يلي مجموعة من التوصيات التي يمكن أن تسهم

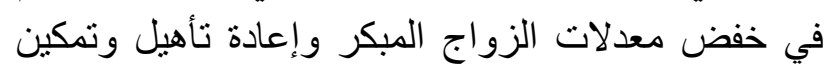

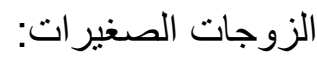

تشجيع الأسر وخاصة في المناطق الأكثر احتياجا (ريف

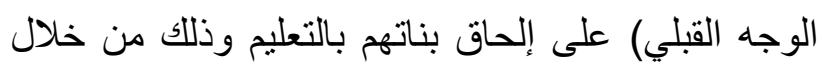

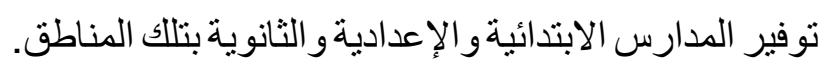

ويمكن أن يتم تحفيز الأسر من خلال منح مكافآت مادية

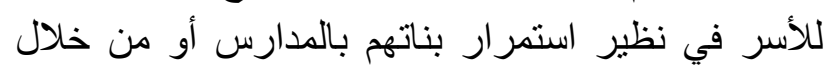

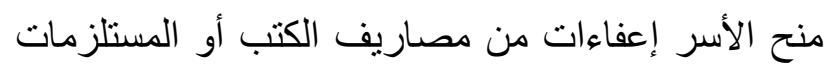
المدرسية.

ويمكن أن تلعب المدارس المجتمعية ذات الفصل الواحد

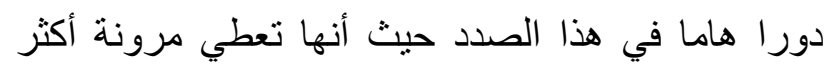
للطلاب في مواعيد الدراسة ومن ثم يمكنهم الجمع بين هين مساعدة الأهل و الالتحاق بالتعليم.

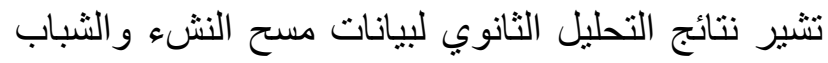

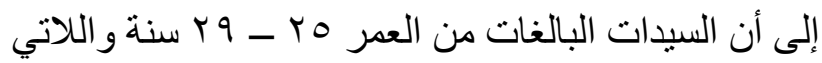

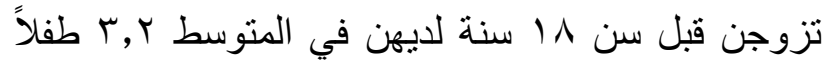

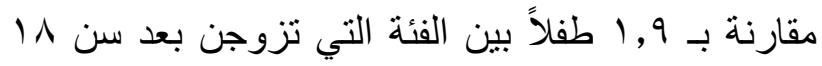

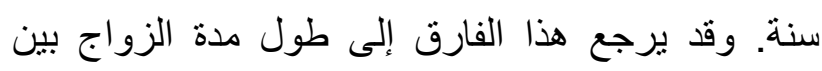

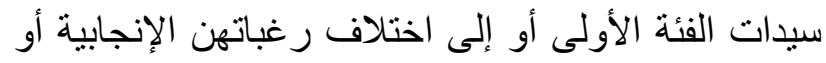
خصائصهن الاجتماعية أو لكل هذه العو امل مجتمعة. أما عن احتمالات حدوث الإجهاض أو و لادة طفل ميت

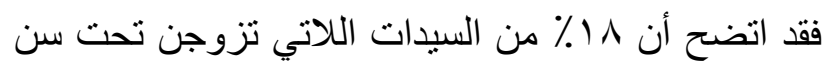

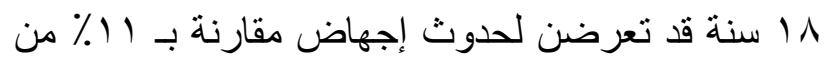

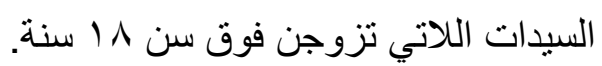

وفي سياق متصل افادت ^٪ من السيدات اللاتي تزوجن

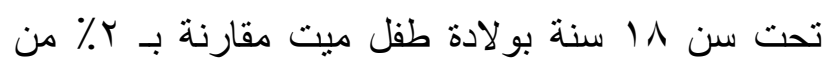

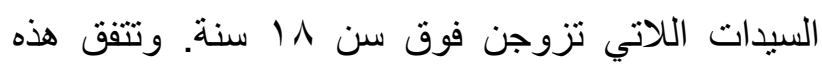

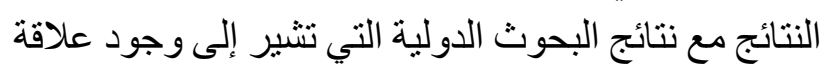
بين الحمل المبكر والمتكرر ومضاعفات الو لادة.

\section{الخلاصة}

مما سبق يتضح لنا أن هناك ثمة فروق و اضحة بين شريحة

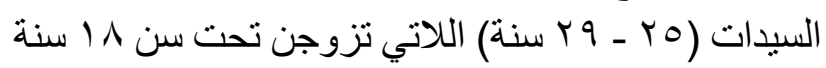

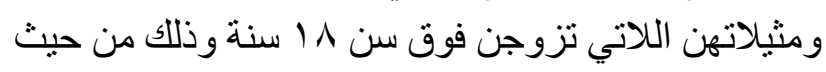
الخصائص الاجتماعية والاقتصادية و الاتجاهات ولتون والر أي

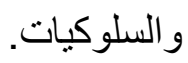

و الجدير بالإشارة أن تلك الاختلافات بين الشريحتين قد لا

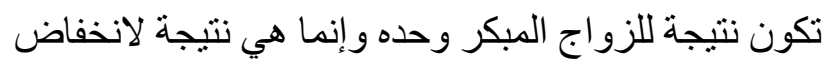

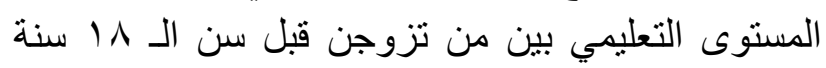

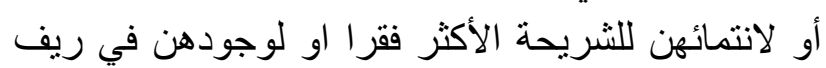

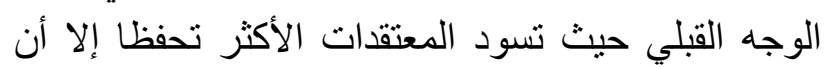
التأثثر السلبي لهذه العو امل قد تتضاعف حدته مع الزواج المبكر.

وفي جميع الأحوال فإن هذه النتائج تحتم علينا التفكير في برامج وسياسات تركز على تللك الفئات المهمشة (مثال:

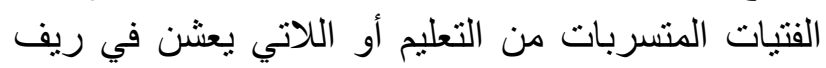

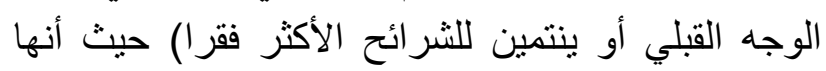


بصحتهن وصحة أبنائهن وتتظيم الأسرة وكذلك ربطهن

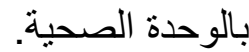

\section{تمكين و تأهيل الزوجات الصغيرات:}

وذلك عن طريق توفير فرص التعليم والتوظيف لهن. ويوجد العديد من البرامج التي تقوم بتتفيذها الجمعيات

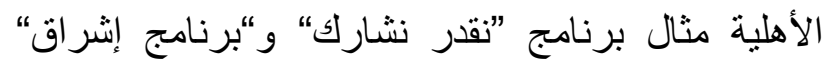
وغيرها من البرامج التي توفر أماكن آمنة للفتيات ومن بناهن خلالها يتم إكسابهن المهارات الاجتماعية والاقتصادية

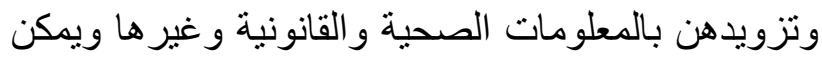

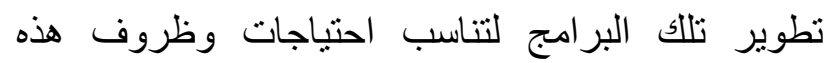
الثريحة من السيدات وإكسابهن المهارات الاجتماعية

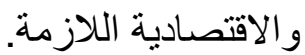

وينبغي دعم الجمعيات الأهلية للتوسع في تللك البرامج

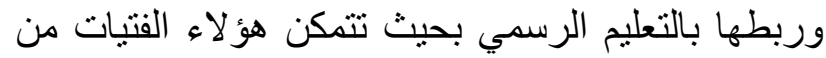

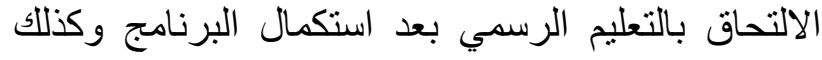

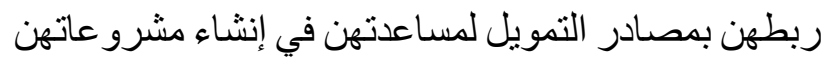
الصغيرة ومساعدتهن في تسويق منتجاتهن.

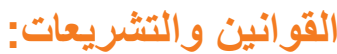

ينبغي تعديل القانون الحالي بحيث تمتد العقوبة لتشمل كافة صور الزواج دون السن القانونية (سواء بعقد رسمي أو غير التون

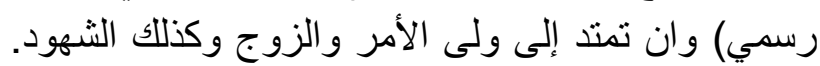
كما ينبغى تغليظ العقوبة المالية و التى تبلغ حاليا ـ . . ج جنيه حتى تمثل رادعاً لكل من يشارك فى ابر ام هذا العقد. كما ينبغي تغليظ العقوبة المالية (الغر امة) حيث ان العرف جرى على انها الأقرب للحكم بها للاعتبار ات الاجتماعية. كما ينبغي تفعيل القانون الذي بنص الإلى على معاقبة ولي

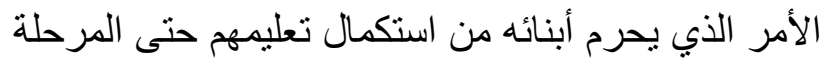
الثانوية.

وأخير ا يجب إعادة النظر في جميع التشريعات والقرارات الوزارية التي تحول دون التحاق الفتيات المتزوجات بالتعليم الرسمي المنتظم وتلك التي تحول دون دون حصول الزوجات الصغيرات على خدمات الصحة الإنجابية من دن دون

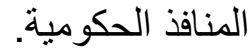

ينبغي تطوير المناهج التعليمية بحيث تتطرق إلى

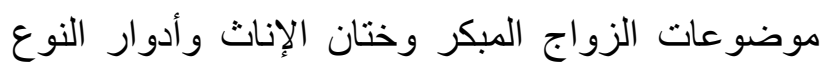

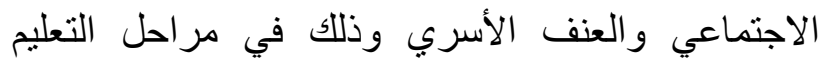
المختلفة. كما ينبغي بناء مهار ات المعلمين ليتمكنوا من الإن تدريس تللك الموضو عات بشكل جيد.

\section{رفع الوعي المجتمعي:}

من خلال وسائل الإعلام والمؤسسات الدينية والجمعيات

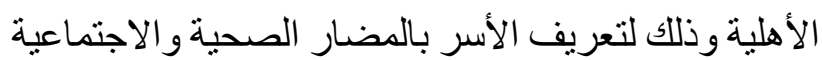

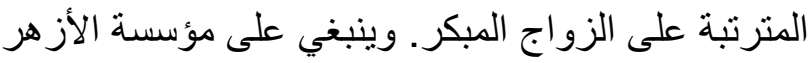

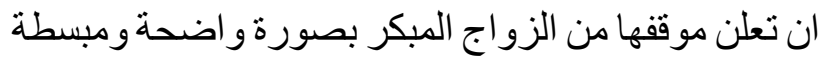

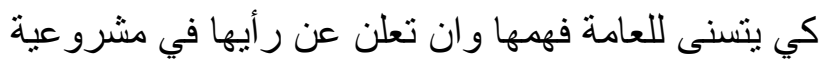

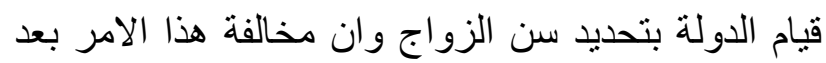
تحديده من قبل اولي الامر (الدولة) يعد مخالفة شرعية

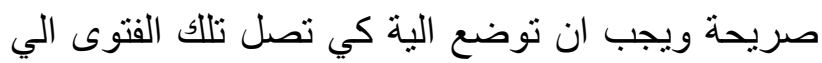
العامة بيسر وسهولة.

وبالإضافة للتركيز على شريحة الآباء و الأمهات ينبغي أن تركز مجهودات رفع الوعي على شريحة الثباب لتعريفهم بالمز ايا التي سوف تعود عليهم و على أبنائهم في المستقبل

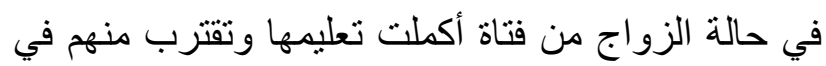
العمر.

\section{خدمات الصحة الإنجابية:}

ينبغي الاستفادة من كل الفرص لتعريف المترددين على

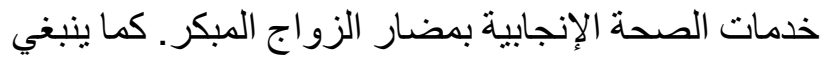

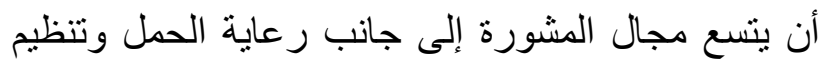
الأسرة وصحة الطفل ليشمل الموضو عات المختلفة مثال

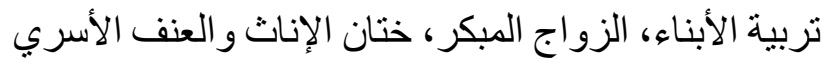

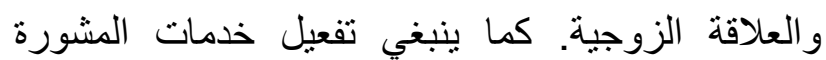

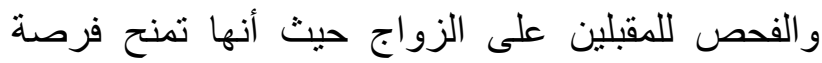

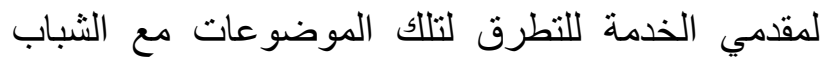
و الثابات المقبلين على الزو اج. لمعله

ويمكن للرائدة الريفية القيام بدور أساسي في الوصول إلى الزوجات الصغيرات ورفع و عيهن بالأمور الخاصة التهية 
يتقام مجلس السكان الدولي بخالص الثكر للأستاذة

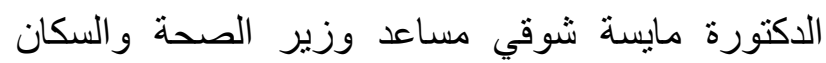
والأستاذ الاكتور طارق توفيق مقرد الدجلس القومي ولئي

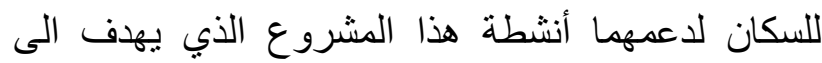
القضاء على الزواج المبكر في مصر وتلبية التئية احتياجات

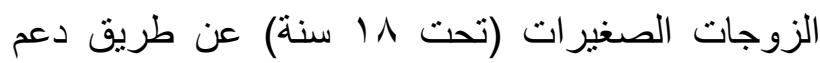
السياسات المبنية على الأدلة العلمية.

كما يتقدم مجلس السكان الدولي بخالص الثكر لمؤسسة فورد لاعمها لهذا الملخص وباقي أنثطة المشروع.

أخيرا نتوجه بعميق الثكر للزملاء بمجلس السكان الدولي

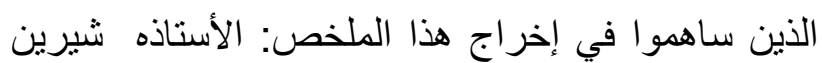

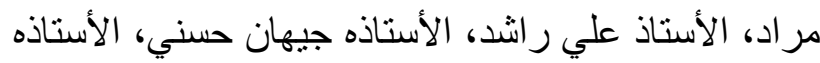

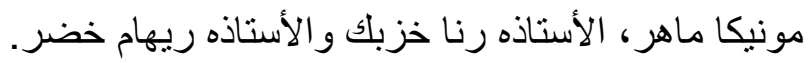

وأخيراً وليس آخراً مطلوب إجراء المزيد من البحوث

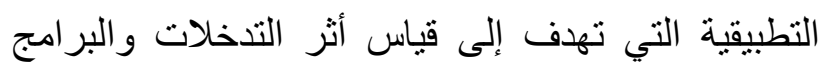
المختلفة في خفض معدلات الزواج النيات المبكر وتمكين وتأهيل

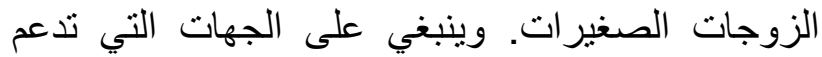

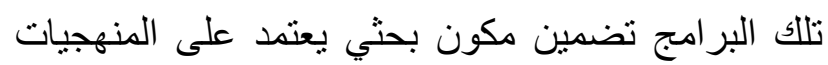
القوية لتقييم الآثار قصيرة وطويلة المدى لتلاكل التدخلات

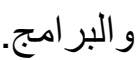

كجلس السكان الدولي 10 ـــ: مسح النشء والثباب لعام ـ ا ب. ا، القاهرة، مجلس السكان الدولي.

مجلس السكان الدولي وقسم الصحة العامة بجامعة أسبوط

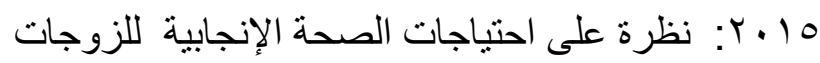

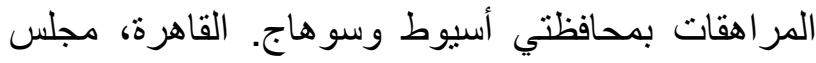

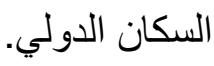




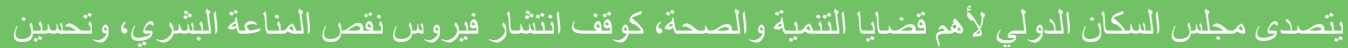

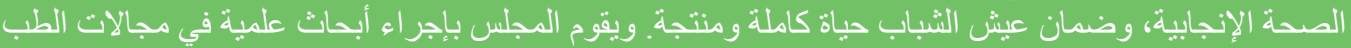

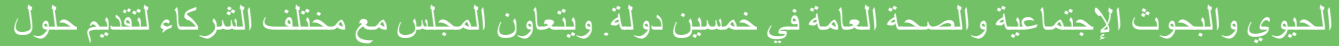

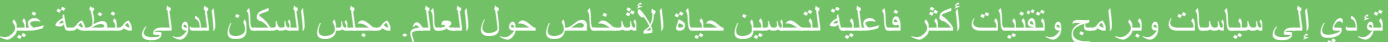

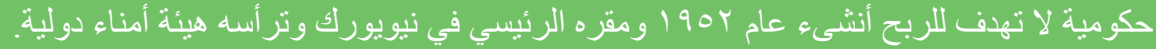

Population Council

One Dag Hammarskjold Plaza

New York, NY 10017

$$
\begin{aligned}
& \text { مجلس السكان الدولي - مصر }
\end{aligned}
$$

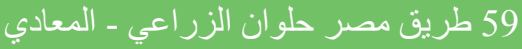

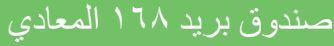

$$
\begin{aligned}
& \text { القاهرة - مصر بل مصر }
\end{aligned}
$$

$$
\begin{aligned}
& \text { هاتف: }
\end{aligned}
$$

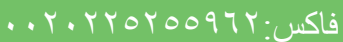

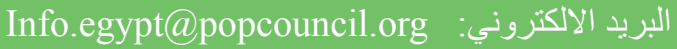

الموقع الالكترونى: www.popcouncil.org الكرني:

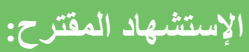

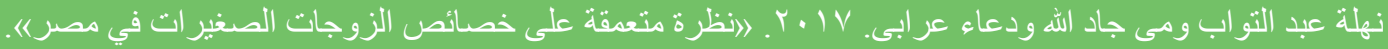

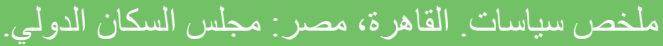

مجلس السكان الدولى r. IV C

\section{POPULATION

